Full paper submitted for publication in Journal of Applied Polymer Science

JOURNAL OF APPLIED POLYMER SCIENCE

VOLUME 130, ISSUE 5, PAGES 3365-3373, DECEMBER 5, 2013

DOI: 10.1002/app.39585

http://onlinelibrary.wiley.com/doi/10.1002/app.39585/abstract

\title{
Effect of molecular architecture on the crystalline structure and stiffness of iPP homopolymers: modeling based on annealing experiments
}

\author{
Zsuzsanna Horváth $^{1,2}$, Alfréd Menyhárd ${ }^{1,2}$, Petar Doshev ${ }^{3}$, Markus Gahleitner ${ }^{3}$, Cornelia Kock ${ }^{3}$, Saeid \\ Kheirandish ${ }^{3}$, József Varga ${ }^{1,2}$ and Béla Pukánszky ${ }^{1,2}$ \\ ${ }^{1}$ Laboratory of Plastics and Rubber Technology, Department of Physical Chemistry and Materials Science, \\ Budapest University of Technology and Economics, H-1521 Budapest, P.O. Box 91, Hungary \\ ${ }^{2}$ Institute of Materials Science and Environmental Chemistry, Research Center for Natural Sciences, \\ Hungarian Academy of Sciences, H-1525 Budapest, P.O. Box 17, Hungary \\ ${ }^{3}$ Borealis Polyolefine GmbH, St.-Peter-Strasse 25, A-4021 Linz, Austria \\ Correspondence to: Alfréd Menyhárd (Email: amenyhard@mail.bme.hu)
}

\begin{abstract}
Five PP homopolymers were selected and their molecular structure was thoroughly characterized to determine the effect of molecular architecture on their annealing behavior and on the ultimate stiffness achieved by heat treatment. Molecular mass and its distribution were characterized by rheological measurements, while chain regularity was determined by calorimetry, by the stepwise isothermal segregation technique (SIST). The samples were annealed in two different ways. Tensile bars were treated in an oven at $165^{\circ} \mathrm{C}$ for increasing times to determine changes in stiffness. Various defects developed during the annealing of tensile specimens that did not allow the reliable determination of modulus by direct measurement. On the other hand, the second approach, the annealing of small samples in a DSC cell clearly showed the changes occurring in crystalline structure and also the effect of nucleation and molecular architecture on them. The large molecular weight fraction used to facilitate nucleation hinders crystal perfection, while the presence of a heterogeneous nucleating agent increases overall crystallinity, but does not influence recrystallization during annealing. Melting traces were transformed into lamella thickness distributions, from which average lamella thickness was derived. Lamella thickness and crystallinity, the independent variables of the empirical equation used for the calculation of modulus, were extrapolated to infinite annealing time to predict maximum stiffness. The
\end{abstract}


Full paper submitted for publication in Journal of Applied Polymer Science

value obtained, 3.5 GPa, is very far from the theoretically predicted $40 \mathrm{GPa}$ of oriented crystals, which cannot be achieved under practical conditions.

Keywords: polypropylene, annealing, crystalline structure, maximum stiffness, modeling, modulus prediction

\section{INTRODUCTION}

Polypropylene is one of the commodity polymers used in large quantities because of its very advantageous price/performance ratio ${ }^{1,2}$. Its overall property combination is excellent offering good stiffness, impact resistance and optical properties depending on the grade. Ever increasing demand for improving properties pushes the limits of existing property ranges to extreme levels. One of the most important properties of materials used in structural applications is stiffness, often a limiting factor for polypropylene. The modulus of engineering thermoplastics is somewhere in the range of 2.5-3.5 GPa. Regular PP grades have a stiffness of 1.4-1.5 GPa, and only special grades reach values of 2.2-2.4 GPa ${ }^{1,3}$. Model calculations indicated that the theoretical modulus of isotactic PP is approximately $40 \mathrm{GPa}$ for oriented samples ${ }^{4,5}$, much larger than actual values measured on commercial PP. One of the goals of technical development is to increase the stiffness of PP beyond current values. However, the practical limitations to increase stiffness in commercially produced polymers remains an open question even today.

The properties of crystalline polymers are determined by their structure which can be modified by two main approaches: i) to control molecular structure and increase chain regularity ${ }^{6,7}$ or ii) to use nucleating agents ${ }^{8-14}$. Modern polymerization and catalyst technology reached very high levels, further progress is difficult. On the other hand, a large number of nucleating agents have been developed recently, some of which are extremely efficient. Several of them are used also in industrial practice. The proper combination of the two approaches resulted in the 2.2-2.4 GPa stiffness for special PP grades available commercially. Besides the usual nucleating agents used in everyday practice, recently another approach, the addition of a small amount of ultrahigh molecular weight (UHMW) fraction is also used to facilitate nucleation. This phenomenon has first been demonstrated in the group of Kornfield for polypropylene $e^{15,16}$, but it was also extended to polyethylene ${ }^{17,18}$. The positive effect of an increase in polydispersity on iPP crystallization under flow and on the resulting crystal morphology has been documented again only recently ${ }^{19}$.

Crystalline structure can be modified also by annealing, by the heat treatment of specimens or products $^{20,21}$. Although the approach has limitations for practical use, annealing was shown to modify all aspects of crystalline structure and consequently properties ${ }^{22-25}$. Heat treatment at high temperature, close to the melting range of the polymer, results in the perfection of crystals, the increase of lamella thickness and crystallinity ${ }^{26-29}$, and in the decrease of the number of tie molecules. The wide-angle branched tangential lamellae (T-lamella) melt within the crosshatched structure and recrystallize into a more perfect architecture during annealing ${ }^{30}$. A change in crystal modification might also take place during annealing, because the metastable modification of polymorphic polymers can transform into the more stable form, e.g. $\beta$-iPP may recrystallize into the thermodynamically stable $\alpha$-form ${ }^{31}$. Similarly, the metastable smectic form of iPP transforms into the $\alpha$-modification during heat treatment ${ }^{32}$. Although practically not very relevant, annealing may offer a possibility to determine the upper limit of stiffness achievable with commercial polymers. 
Full paper submitted for publication in Journal of Applied Polymer Science

In a preliminary study we used three types of commercial polymers to explore the possibility of increasing the modulus of PP by annealing. Grades were used i) with heterogeneous nucleation, ii) with the addition of a UHMW fraction and iii) without any nucleating agent. The studied polymers behaved quite differently during annealing; some of them transformed completely, while others only partially into more perfect crystals. Based on the results it was difficult to decide if differences in nucleation or molecular weight distribution (MWD) resulted in the dissimilar behavior. As a consequence, one of the goals of the present study was to determine the effect of molecular architecture and nucleation on the annealing behavior of various polypropylene homopolymers. Specimens were prepared and annealed to determine the upper limit of stiffness achievable by this method. Further study was carried out on small samples in DSC, and modulus was predicted by model calculations based on experimentally determined moduli and DSC traces. The consequences for practice and the possibilities to approach the theoretical modulus value of $40 \mathrm{GPa}$ are discussed at the end of the paper.

\section{EXPERIMENTAL}

Five PP homopolymers were supplied by Borealis Polyolefine $\mathrm{GmbH}$ for the study; two of these were commercial grades (PP2, NPP1), one came from an experimental process using dynamic hydrogen feed (PP1) $)^{33}$ and two from experimental multimodal polymerizations in a Borstar ${ }^{\mathrm{TM}}$ PP pilot unit (NPP2, NPP3 $)^{34}$. The polymers differed in nucleation, molecular mass and in the presence or absence of an UHMW fraction. The melt flow rate (MFR, ISO 1133) at $230{ }^{\circ} \mathrm{C}$ and $2.16 \mathrm{~kg}$ of the polymers changed between 0.2 and $2.0 \mathrm{dg} \mathrm{min}{ }^{-1}$. The identification of the polymers and the factors studied (nucleation, UHMW fraction) can be found in Table 1.

TABLE 1 Identification of the polymers used in the study

\begin{tabular}{|c|c|c|c|}
\hline Sample & Nucleation & MWD & $\begin{array}{c}\text { MFR } \\
\left(\mathrm{dg} \min ^{-1}\right)\end{array}$ \\
\hline PP1 & no & broad $^{\mathrm{a}}$ & 2.00 \\
\hline PP2 & no & standard & 0.20 \\
\hline NPP1 & yes & standard & 2.00 \\
\hline NPP2 & yes & broad $^{a}$ & 2.00 \\
\hline NPP3 & yes & broad $^{a}$ & 0.65 \\
\hline
\end{tabular}

${ }^{a}$ the samples contain an ultra high molecular weight (UHMW) fraction

Molecular architecture was characterized by stepwise isothermal segregation (SIST). The SIST experiments were carried out using a Perkin Elmer DSC 7 apparatus between 160 and $100{ }^{\circ} \mathrm{C}$. After the elimination of thermal and mechanical prehistory at $220^{\circ} \mathrm{C}$ for $5 \mathrm{~min}$, the samples were cooled to $160{ }^{\circ} \mathrm{C}$ at a cooling rate of $80^{\circ} \mathrm{Cmin}^{-1}$ and held there for 3 hours. Subsequently, the samples were taken to the next crystallization temperature $\left(150^{\circ} \mathrm{C}\right)$ and kept there for another 3 hours. Each temperature ramp took 3 hours and each step was $10^{\circ} \mathrm{C}$. After the final crystallization step at $100^{\circ} \mathrm{C}$ the samples were reheated again at a heating rate of $10^{\circ} \mathrm{Cmin}^{-1}$ and melting traces were recorded. Regular sequence length was obtained and calculated according to the method described by Garroff et al ${ }^{7}$. Rheology was used for the determination of average molecular weight and molecular weight distribution (MWD), because the presence of the UHMW fraction made GPC measurements impossible. The measurements were done by using an Anton Paar UDS 200 oscillatory rheometer at $200{ }^{\circ} \mathrm{C}$ in plate-plate geometry according to ISO 6271-10. Frequency sweeps were done between 0.02 and $600 \mathrm{~Hz}$ to determine storage and loss moduli 
$\left(G^{\prime}, G^{\prime \prime}\right)$. The shear dependence of viscosity (Fig. 1) was calculated by assuming the validity of the CoxMerz rule.

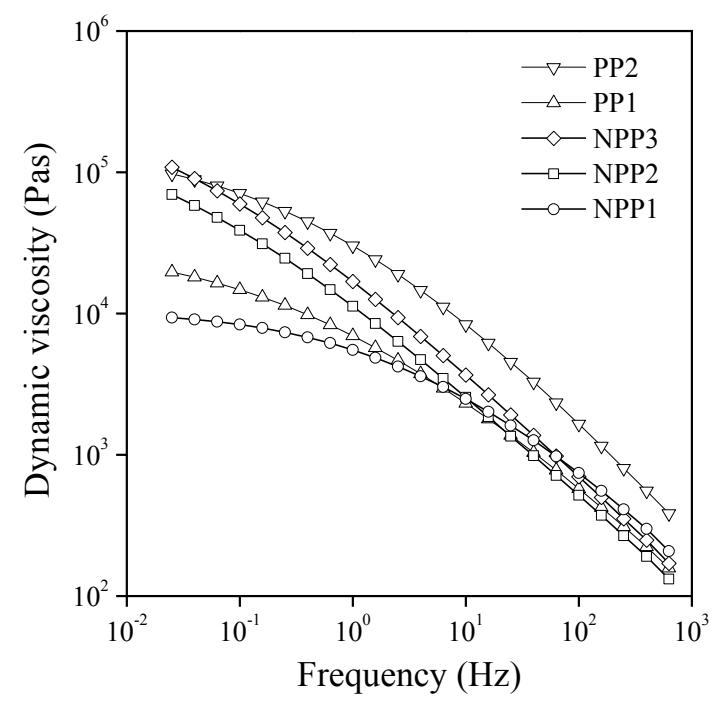

FIGURE 1 Melt viscosity curves $\left(200^{\circ} \mathrm{C}\right)$ for the five PP homopolymers studied. Symbols: $(\Delta)$ PP1, $(\nabla)$ PP2, (O) NPP1, (口) NPP2, ( $\diamond)$ NPP3

Molecular weight was deduced from extrapolated zero shear viscosity $\left(\eta_{0}\right)$ with the help of the correlation $^{35}$

$$
M_{w}=32.38 \eta_{0}^{0.2344}
$$

while MWD was estimated by the polydispersity index $(P I)$ calculated from the cross-over modulus $\left(G_{c}\right)^{36}$

$$
P I=\frac{10^{5}}{G_{c}}
$$

A terminal relaxation time $\left(\tau_{r}\right)$ was also calculated to further characterize the effect of the high molecular weight component on the crystallization and stiffness of the polymers. To achieve this goal, a continuous relaxation time spectrum $H(\tau)$ was calculated from the storage and loss moduli $\left[G^{\prime}(\omega), G^{\prime \prime}(\omega)\right]$ using the Rheoplus 123 Software V2.66 of Anton Paar. The underlying principles of the calculations have been described for example by Mezger ${ }^{37}$. A bandwidth of $1 \%$ was set and 50 values of relaxation time determined using automatic limit selection. The regularization parameter $\alpha$ was set at 0.01 and a cubic spline was used for smoothing. The terminal relaxation time, $\tau_{r}$, was calculated at a relaxation strength $H(\tau)$ of $10 \mathrm{~Pa}$. The most important characteristics of the polymers used in the study are compiled in Table 2.

Plates with $1 \mathrm{~mm}$ thickness were compression molded from granules at $200{ }^{\circ} \mathrm{C}, 100$ bar with 5 min compression time and then the plates were cooled down to room temperature. Tensile bars were cut from the plates for the annealing study. They were annealed at $165^{\circ} \mathrm{C}$ for $0,15,30,60,120$ and 480 
min. The modulus of the reference and annealed specimens was determined using an Instron 5566 tensile testing machine at $0.5 \mathrm{~mm} \mathrm{~min}^{-1}$ cross-head speed and $115 \mathrm{~mm}$ gauge length. Annealing was done also in a DSC cell at the same temperature and times as for mechanical testing. The samples were heated to $220^{\circ} \mathrm{C}$ at $10^{\circ} \mathrm{Cmin}^{-1}$ heating rate and held there for $5 \mathrm{~min}$ to erase previous thermal history, then cooled down to room temperature with the same rate. Subsequently they were heated to the temperature of annealing and kept there for the respective annealing times. Finally the samples were cooled to room temperature and then heated again to $220^{\circ} \mathrm{C}$ to record melting characteristics. The distribution of lamella thickness and crystallinity were determined from the melting traces ${ }^{38}$.

\section{RESULTS AND DISCUSSION}

Before discussing the results of the annealing experiments, we consider polymer characteristics determined by various methods. After the presentation of experimental moduli of annealed samples, we show the effect of annealing on crystalline structure, and the characteristics derived from the DSC traces. The way to predict stiffness from these parameters and ultimate moduli are presented in the final section of the paper.

TABLE 2 Molecular characteristics of the studied iPP homopolymers

\begin{tabular}{|c|c|c|c|c|c|c|c|}
\hline \multirow[b]{2}{*}{ Polymer } & \multirow[b]{2}{*}{$\begin{array}{l}\text { Seq. length } \\
\text { (monomer) }\end{array}$} & \multicolumn{6}{|c|}{ Rheology } \\
\hline & & $\begin{array}{c}\eta_{0} \\
\text { (Pas) }\end{array}$ & $\begin{array}{c}M_{w} \\
\left(\mathrm{kgmol}^{-1}\right)\end{array}$ & $\begin{array}{c}\omega_{c}^{b} \\
\left(\operatorname{rad~s}{ }^{-1}\right)\end{array}$ & $\begin{array}{c}G_{c} \\
(\mathrm{kPa})\end{array}$ & $\begin{array}{c}P I \\
\left(\mathrm{~Pa}^{-1}\right)\end{array}$ & $\begin{array}{l}\tau_{r}^{\mathrm{c}} \\
(\mathrm{s})\end{array}$ \\
\hline PP1 & 88 & 34600 & 607 & 4.9 & 11.6 & 8.6 & 240 \\
\hline PP2 & 93 & 92700 & 765 & 1.6 & 26.9 & 3.7 & 2118 \\
\hline NPP1 & 93 & 8280 & 434 & 9.9 & 17.4 & 5.7 & 45 \\
\hline NPP2 & 101 & 140900 & 843 & 0.2 & 3.7 & 26.7 & 3340 \\
\hline NPP3 & 91 & 219600 & 936 & 0.2 & 5.2 & 19.2 & 11704 \\
\hline
\end{tabular}

a determined by SIST

${ }^{b}$ cross-over frequency

'relaxation time at $H(\tau)=10 \mathrm{~Pa}$

\section{Polymer characteristics}

The analysis of the characteristics listed in Table 2 reveals that in spite of the presence of the high molecular weight fraction, the weight average molecular weight and other characteristics depending on it (zero shear viscosity, $\eta_{0}$, relaxation time, $\tau_{r}$ ) are surprisingly small for the PP1 sample. The isotactic sequence length, i.e. chain regularity, is also the smallest for this polymer and it behaved dissimilarly from the others in the annealing study as well.

It is interesting to check the correlation among the various parameters used for the characterization of the polymers. Despite the variation in the shear dependence of viscosity for the studied samples (see Fig. 1), a very close relationship was found among all quantities derived from the rheological measurements. One example is presented in Fig. 2 showing the correlation of relaxation time and molecular weight. The figure also emphasizes the wide range of properties covered by the polymers used in this study. Much less or no correlation exists between chain regularity and characteristics related to molecular weight and MWD. Zero shear viscosity is plotted against isotactic sequence length in Fig. 3. The complete lack of correlation indicates clearly that the two types of 
characteristics are independent of each other. This independence may facilitate the identification of the main factor determining annealing behavior and help to define those which influence the final modulus of the polymer.

\section{Experimental stiffness of annealed specimens}

Specimens prepared from the studied polymers were annealed and their stiffness determined according to the protocol described in the experimental part. The results are presented for three of the polymers in Fig. 4, which represent typical behavior observed in this study.

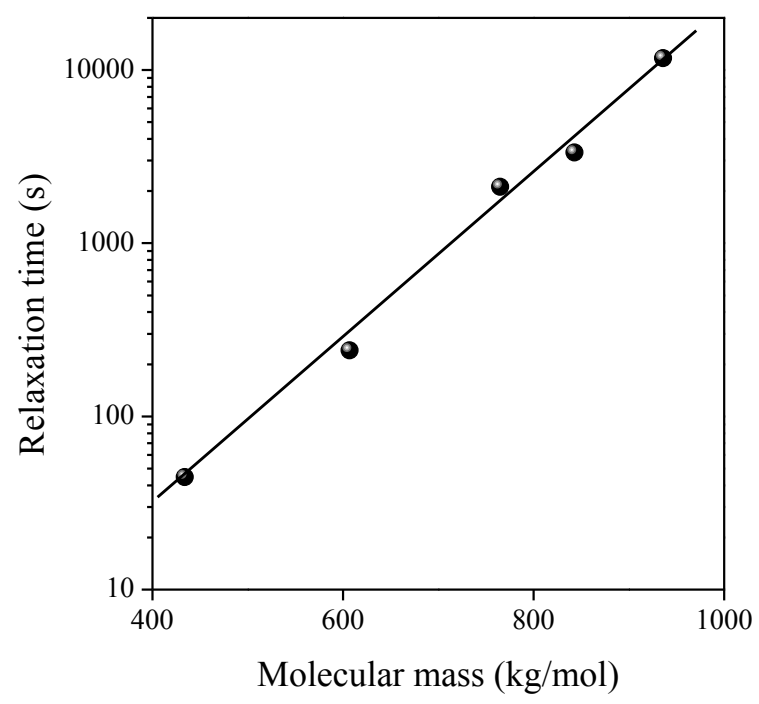

FIGURE 2 Close correlation between polymer characteristics determined by rheology. Relaxation time measured at $H(\tau)=10 \mathrm{~Pa}$ is plotted against weight average molecular weight derived from cross-over modulus (see Eq. 2).

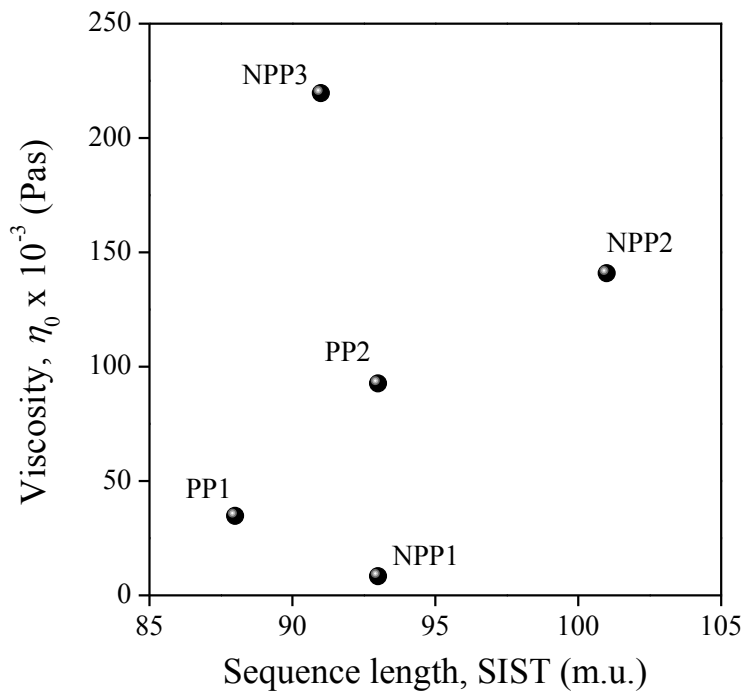


FIGURE 3 Complete lack of correlation between parameters characterizing chain regularity and the size of the molecules; zero shear viscosity plotted against isotactic sequence length.

The interpretation of the correlations presented in Fig. 4 is complicated, because stiffness does not increase as expected. Some increase can be observed for PP1 and NPP1, but a drop occurs in stiffness in the former case from an initial larger value (see stiffness at $t_{a}=0 \mathrm{~min}$ ), while modulus decreases continuously with annealing time for NPP3. The relatively large increase in stiffness from about 1.9 to $2.8 \mathrm{GPa}$ is exceptional in the case of NPP1, but modulus goes through a maximum and decreases after a certain annealing time even in this case.

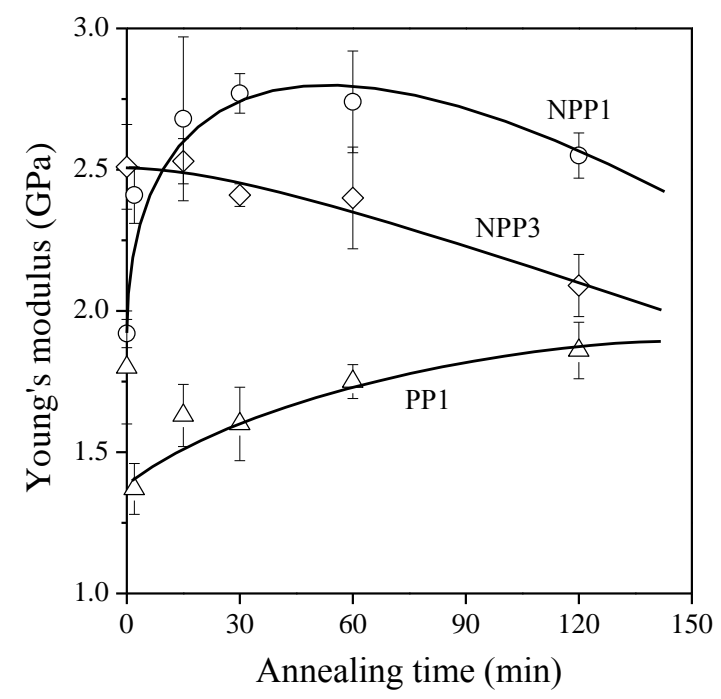

FIGURE 4 Dependence of Young's modulus on annealing time for three selected polypropylenes.

Symbols: $(\Delta)$ PP1, (O) NPP1, $(\diamond)$ NPP3.

The unexpected and quite unreliable results originated from experimental difficulties encountered during annealing. Cracking, voiding and other defects were observed on most of the specimens especially after longer annealing times. Similar problems were encountered and reported also by others $[x]$ earlier. The number of defects and the extent of damage depended also on the characteristics of the polymer studied. Accordingly, stiffness could not be determined with any reliability and thus the ultimate limit of stiffness, which might be achieved by annealing, could not be estimated either. As a consequence, we had to find another way to follow changes in crystalline structure during annealing and to relate them to mechanical properties and especially to stiffness.

\section{Annealing and structure}

Annealing carried out in the DSC pan changed crystalline structure considerably as expected, but quite differently for the various samples. A typical example is shown in Fig. 5 (DSC traces for the other polymers can be seen in the supplementary information) . 


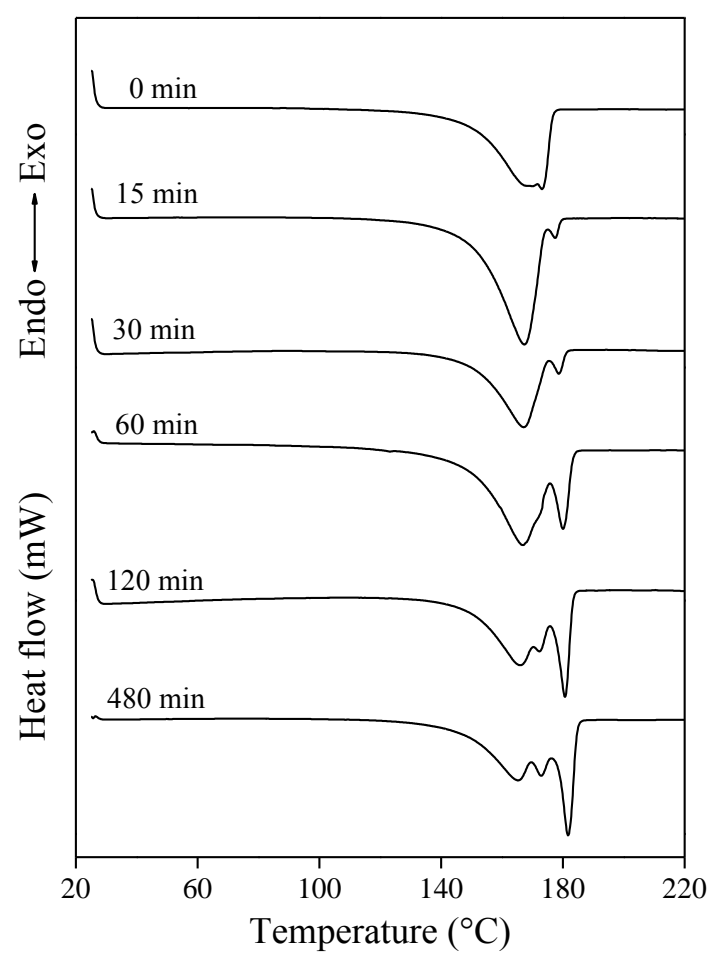

FIGURE 5 Effect of annealing on the crystalline structure of NPP3; melting traces recorded after different annealing times.

The melting traces recorded on the NPP3 polymer after various annealing times indicate the transformation of the polymer into several fractions with different melting temperatures. Although a considerable part of the polymer recrystallizes into a fraction with a melting temperature at around 180 ${ }^{\circ} \mathrm{C}$, a large part forms less perfect crystals. Obviously, some factor hinders crystal perfection and the annealed polymer consists of an assembly of fractions with different lamellar thicknesses and perfection. The results showed that the five polymers studied formed two groups according to their annealing behavior. The three containing the UHMW fraction transform only partially to the most perfect morphology during annealing, while those without it go through complete or almost complete transformation. Obviously nucleation does not hinder or influence crystal perfection, but large molecules do.

Earlier studies have shown that the stiffness of PP is determined by crystallinity and lamella thickness ${ }^{39}$. The relationship between lamella thickness and melting temperature $\left(T_{m}\right)$ is given by the Gibbs-Thompson equation ${ }^{21,40}$

$$
T_{m}=T_{m}^{0}\left(1-\frac{2 \sigma_{e}}{\Delta H_{v}^{0} \ell}\right)
$$

where $T_{m}$ is the actual melting temperature of the polymer, $T_{m}{ }^{0}$ is its equilibrium melting temperature $\left(481 \mathrm{~K}^{41}\right), \sigma_{e}$ is the free energy of the folded surface of the lamella $\left(0.122 \mathrm{~J} \mathrm{~m}^{-2}{ }^{41}\right)$, and $\Delta H_{v}{ }^{0}$ is the equilibrium enthalpy of fusion per unit volume $\left(136.6 \mathrm{~kJ} \mathrm{~m}^{-3}{ }^{41}\right)$. Accordingly, each point of a melting 
trace corresponds to a lamella thickness and the trace can be transformed into lamella thickness distribution by the method of Romankiewicz and Sterzynski ${ }^{38}$ using the equation

$$
\frac{1}{m} \frac{\mathrm{d} m}{\mathrm{~d} \ell}=\frac{1}{\mathrm{~m}} \frac{\mathrm{d} E}{\mathrm{~d} T} \frac{\left(T_{m}^{0}-T_{m}\right) \rho_{c}}{2 \sigma_{e} T_{m}^{0}}
$$

where $m$ is the mass of the crystalline phase, $\boldsymbol{E}$ the enthalpy of fusion and $\rho_{c}$ is the density of the crystals $\left(936 \mathrm{~kg} \mathrm{~m}^{-3}{ }^{42}\right)$. Fig. 6 shows the effect of annealing time on the distribution of lamella thickness for a polymer, which is capable of complete perfection in the time interval used (PP2). We can see that transformation is almost complete indeed, and lamella thickness increases considerably during the annealing experiment.

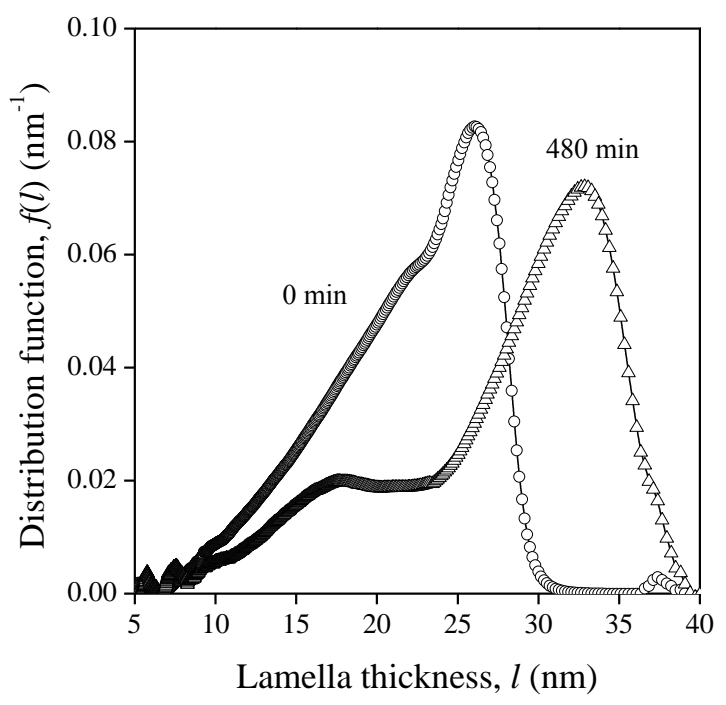

FIGURE 6 Effect of annealing time on the lamella thickness distribution of the PP2 sample. Symbols: (O) $0 \mathrm{~min},(\Delta) 480 \mathrm{~min}$.

In contrast, the polymers containing the UHMW fraction cannot transform completely into the more perfect structure as shown by Fig. 7 comparing representatives of the two groups of polymers. 


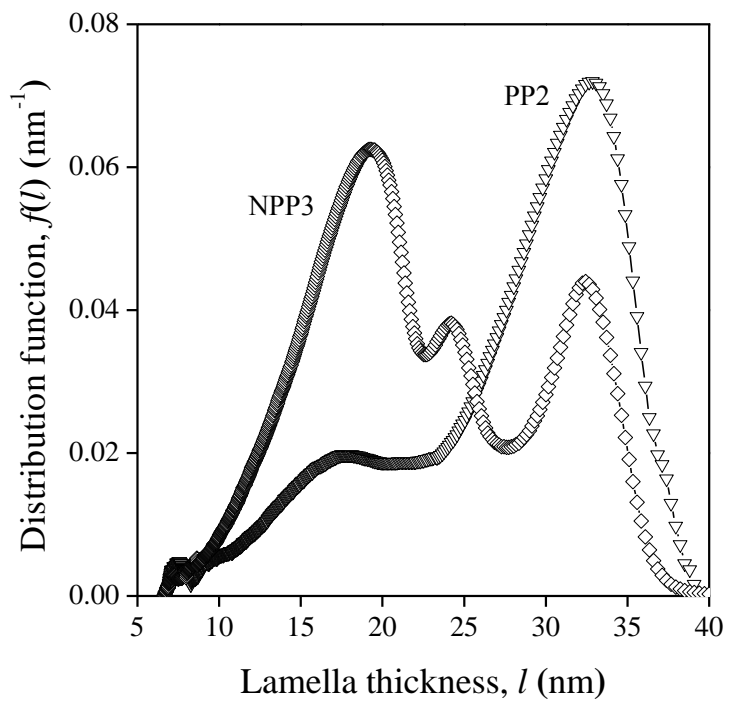

FIGURE 7 Comparison of the lamella thickness distribution of two samples with standard (PP2) and broad (NPP3) molecular weight distribution. Annealing time was $480 \mathrm{~min}$ for both samples. Symbols: $(\nabla)$ PP2, $(\diamond)$ NPP3.

We are able to show the effect of annealing on crystalline structure by DSC measurements, but it is difficult if not impossible to relate these changes to mechanical properties.

\section{Modulus prediction}

Detailed analysis of three polypropylenes, a homopolymer, a random and a heterophase copolymer containing four different nucleating agents in various amounts resulted in an extremely close correlation between crystallization characteristics determined by DSC and the stiffness of injection molded bars. The correlation could be described quantitatively by the empirical equation ${ }^{39}$

$$
E=0.02 T_{c p}+0.025 \Delta H_{c}-3.2
$$

where $E$ is Young's modulus, $T_{c p}$ is the peak temperature $\left({ }^{\circ} \mathrm{C}\right)$, while $\Delta H_{c}$ the heat of crystallization. In spite of the fact that crystallization characteristics were determined on small samples melted first, the simple empirical correlation of Eq. 5 proved to be valid practically for all PP polymers studied by us, but also by others ${ }^{43}$ up to now. The close correlation indicates that the effect of nucleation is similar under the conditions of the DSC study and injection molding. Unfortunately crystallization characteristics are not available in the annealing study, but we have melting traces recorded on annealed samples instead. However, since melting and crystallization characteristics are usually related quite closely, we can hope that the principles developed earlier hold, and if we replace $\Delta H_{c}$ and $T_{c p}$ by the heat of fusion and lamella thickness, we may predict the modulus of annealed PP samples as well. Naturally we must validate the approach and determine the parameters of the correlation first. 
Average lamella thickness can be derived from the distributions shown in Figs. 6 and 7 by

$$
\bar{\ell}=\frac{\int_{0}^{\infty} f(\ell) \ell \mathrm{d} \ell}{\int_{0}^{\infty} f(\ell) \mathrm{d} \ell}
$$

and the results are plotted against annealing time in Fig. 8 for all the polymers studied. We can see that lamella thickness increases with annealing time and approaches saturation at larger times. Very similar correlations were obtained also for the time dependence of the enthalpy of fusion (not shown). The rate of property increase and the final values depend on the characteristics of the polymer. The thickest lamellae grew in the non-nucleated sample with standard MWD, while nucleated samples developed larger final crystallinity than the other two. The average lamella thickness of PP1 shows different characteristics during annealing. It increases first because only a recrystallized perfect fraction is present in the sample at short annealing time. At longer annealing times a less perfect structure develops slowly resulting in a proportional decrease in average lamella thickness. The surprising behavior might be related to the less regular structure of this polymer (see Table 2), but this assumption needs further proof.

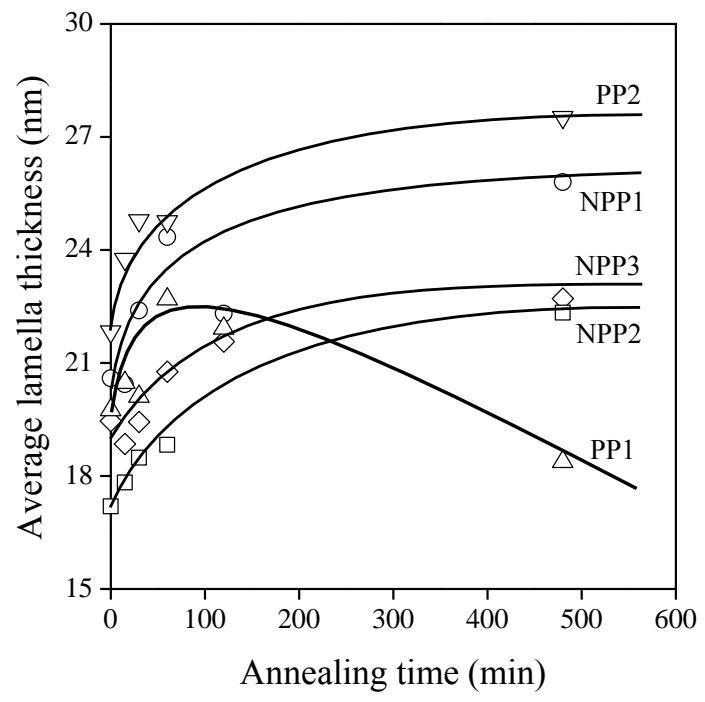

FIGURE 8 Effect of annealing time on the average lamella thickness of the studied samples. Symbols: $(\Delta)$ PP1, ( $\nabla)$ PP2, (O) NPP1, ( $\square$ ) NPP2, ( $\diamond)$ NPP3

The time dependence shown in Fig. 8 allows us the determination of both lamella thickness and the heat of fusion at infinite time. We fitted the empirical equation

$$
y=a+b \exp (-k t)
$$

to the time dependence of the two properties and determined $\ell_{\max }$ and $\Delta H_{m}{ }^{\max }$ for all materials. A typical correlation fitted to the experimental data is presented in Fig. 9 to demonstrate the procedure. 
The calculated maximum values are collected in Table 3 for the five PP polymers studied. We also included selected characteristics of chain structure into the table in order to facilitate seeing their effect on the parameters of crystalline structure. Only approximate values could be determined for PP1. The table clearly shows that $\ell_{\max }$ is the largest for PP2 and NPP1 and smaller for samples containing the UHMW fraction, while larger crystallinity develops in nucleated samples.

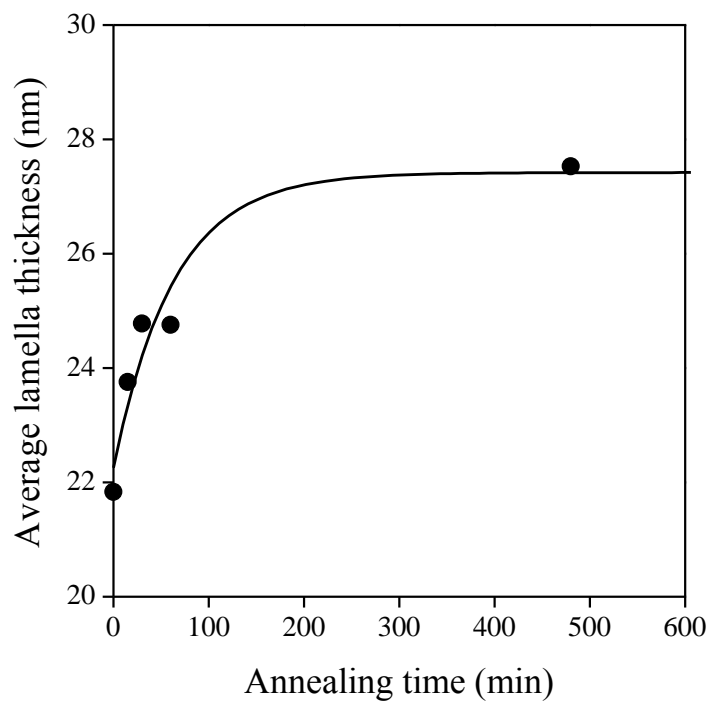

FIGURE 9 Fitting of a saturation function (see Eq. 7) to the time dependence of average lamella thickness for the PP2 sample.

TABLE 3 Prediction of the ultimate modulus of PP homopolymers and comparison to molecular architecture

\begin{tabular}{|c|c|c|c|c|c|c|}
\hline Polymer & $\begin{array}{l}\text { Sequence length } \\
\text { (monomer units) }\end{array}$ & $\begin{array}{c}\eta_{0} \\
\text { (Pas) }\end{array}$ & $\begin{array}{l}\ell_{\max } \\
(\mathrm{nm})\end{array}$ & $\Delta H_{m}^{\max }\left(\mathrm{Jg}^{-1}\right)$ & $\begin{array}{c}\text { Crystallinity, } \alpha^{\max } \\
(\%)\end{array}$ & $\begin{array}{c}E_{\max } \\
(\mathrm{GPa})\end{array}$ \\
\hline PP1 & 88 & 34657 & 22.5 & 123.2 & 83.2 & 2.81 \\
\hline PP2 & 93 & 92700 & 27.5 & 122.2 & 82.6 & 3.20 \\
\hline NPP1 & 93 & 8280 & 25.9 & 136.2 & 92.0 & 3.42 \\
\hline NPP2 & 101 & 140900 & 22.6 & 131.7 & 89.0 & 3.03 \\
\hline NPP3 & 91 & 219600 & 22.8 & 132.1 & 89.3 & 3.06 \\
\hline
\end{tabular}

${ }^{\text {a }}$ determined by SIST

The final step in the prediction is the determination of the proper relationship between melting characteristics (heat of fusion), lamella thickness and stiffness. Using results obtained in an earlier study on injection molded bars, we determined lamella thickness and the heat of fusion for those samples and derived the following correlation to describe the relationship between stiffness and the characteristics of crystalline structure

$$
E=0.082 \ell+0.025 \Delta H_{m}-2.15
$$


The correlation of measured and calculated moduli is presented in Fig. 10. The relationship is less close than the one obtained between modulus and crystallization characteristics earlier ${ }^{39}$, but this is expected. Nevertheless, Fig. 10 clearly proves that the modulus of PP is determined by lamella thickness and crystallinity.

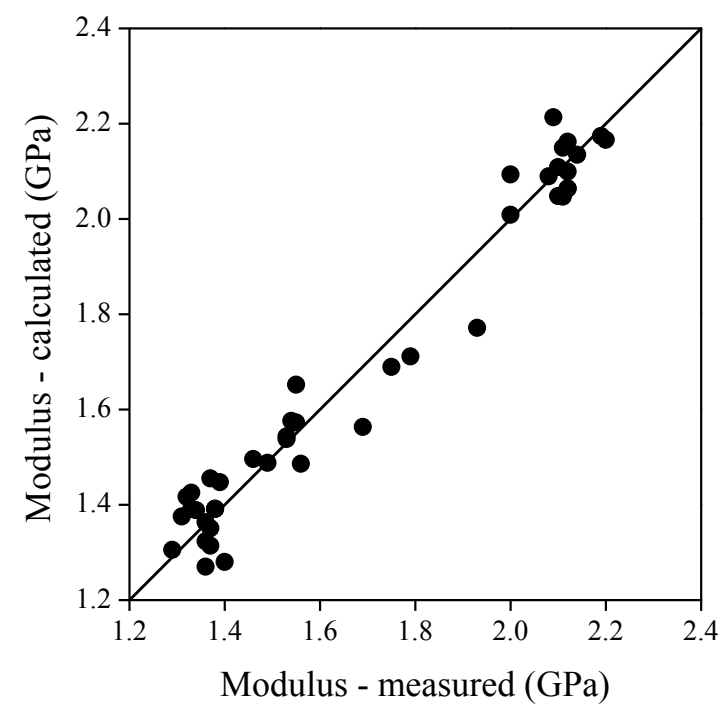

FIGURE 10 Correlation of measured modulus with stiffness calculated from melting characteristics determined by DSC (see Eq. 8) for various nucleated PP homopolymers.

We introduced the $\ell_{\max }$ and $\Delta H_{m}{ }^{\max }$ values derived from the annealing process (see columns 4 and 5 in Table 3 ) into Eq. 8 and predicted the maximum stiffness achievable by annealing under our conditions. The results are collected in the last column of Table 3. The largest modulus achieved by annealing under our conditions is around $3.5 \mathrm{GPa}$, which is very far from the theoretical value of $40 \mathrm{GPa}$ obtained for oriented crystals. We obviously cannot expect a polymer with randomly oriented imperfect crystals to reach the stiffness of a material, in which perfect crystals are oriented in the direction of the load as assumed by the model calculations. The ultra high molecular weight fraction hinders crystal perfection and does not allow reaching large stiffness. The peculiar behavior of PP1 needs further study.

We made an attempt to analyze the effect of molecular architecture on $E_{\max }$, which was complicated by several factors. The simultaneous effect of chain regularity and molecular weight, the particular behavior of the PP1 sample and the relatively small number of polymers studied all increased uncertainty and the difficulties to draw general conclusions. Nevertheless, we could establish that chain regularity increases the maximum stiffness achieved that is not very surprising, while increasing molecular weight decreases its value. The latter effect is demonstrated quite clearly by Fig. 11 showing the correlation of $E_{\max }$ and zero shear viscosity. Apart from the deviating point of the PP1 sample, which might be explained again by its irregularity, the correlation is relatively close and demonstrates well the effect of kinetic factors in crystallization and crystal perfection during annealing. 


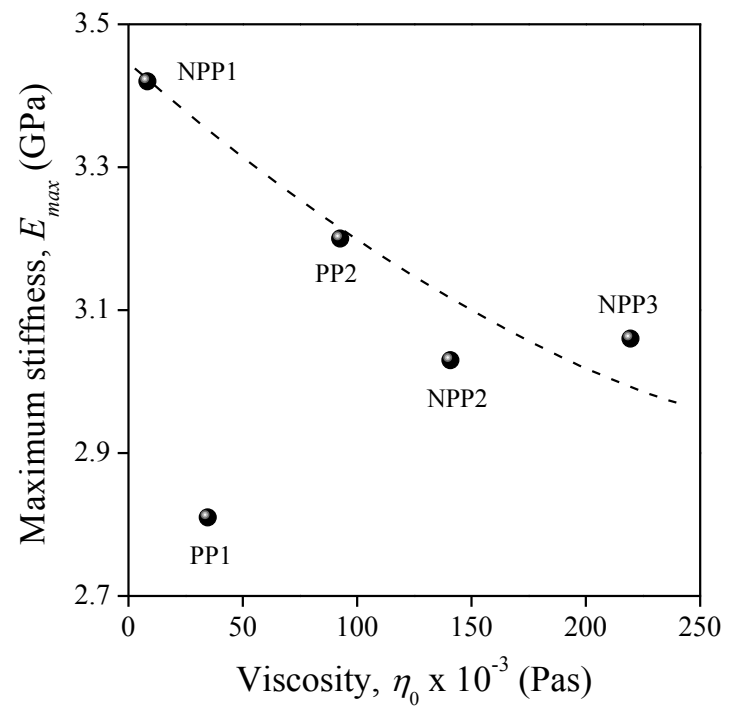

FIGURE 11 Effect of molecular weight $\left(\eta_{0}\right)$ on the maximum stiffness $\left(E_{\max }\right)$ achieved in PP homopolymers by annealing.

\section{CONCLUSIONS}

The direct determination of the effect of annealing on the stiffness of various PP polymers did not prove to be successful because of technical reasons. Various defects developed in annealed specimens which did not allow the reliable determination of modulus. On the other hand, annealing of small samples in DSC clearly reflected the changes occurring in crystalline structure and also the effect of nucleation and molecular architecture on them. The large molecular weight fraction used to facilitate nucleation hinders crystal perfection, while the presence of a heterogeneous nucleating agent increases overall crystallinity, but does not influence recrystallization. Melting traces were transformed into lamella thickness distributions from which average lamella thickness was derived. Lamella thickness and crystallinity at infinite annealing time was determined by a fitting procedure and maximum stiffness was predicted with the help of an empirical equation relating modulus to lamella thickness and crystallinity. The predicted maximum stiffness of about 3.5 GPa is very far from the theoretical value of $40 \mathrm{GPa}$ of oriented crystals, which cannot be achieved under practical conditions.

\section{ACKNOWLEDGEMENTS}

One of the authors acknowledges the support of the National Scientific Research Fund of Hungary (OTKA Grant No K 68748 and K 101124) for his project on the structure-property correlations of polymeric materials. Another author (Alfréd Menyhárd) would like to express his gratitude to the János Bolyai Research Scholarship of the Hungarian Academy of Sciences for its financial support. 


\section{REFERENCES AND NOTES}

1. Moore, E. P. Polypropylene Handbook: Polymerization, Characterization, Properties, Processing, Applications; Hanser-Gardner Publications, Cincinnati, 1996.

2. Gahleitner, M. Express Polymer Letters 2011, 5, 936.

3. Stern, C.; Frick, A. and Weickert, G. J. Appl. Polym. Sci. 2007, 103, 519.

4. Sawatari, C. and Matsuo, M. Macromolecules 1986, 19, 2653.

5. Kunugi, T. In High-Modulus and High-Strength Polypropylene Fibres and Films, Karger-Kocsis, J., Ed.; Kluver Academic Publ., 1999, 295.

6. Gahleitner, M.; Bachner, C.; Ratajski, E.; Rohaczek, G. and Neissl, W. J. Appl. Polym. Sci. 1999, 73, 2507. és így tovább!!!!

7. Garoff, T.; Virkkunen, V.; Jääskeläinen, P. and Vestberg, T. Eur. Polym. J. 2003, 39, 1679.

8. Binsbergen, F. L. Polymer 1970, 11, 253.

9. Menczel, J. and Varga, J. Journal of Thermal Analysis 1983, 28, 161.

10. Thierry, A.; Fillon, B.; Straupé, C.; Lotz, B. and Wittmann, J. Progress in Colloid and Polymer Science 1992, 87, 28.

11. Sterzynski, T. In Nucleation by Additives in Semi-Crystalline Polymers: Effects on Mechanical Behavior, Brostow, W., Ed.; Hanser Publ., 2000, 254.

12. Blomenhofer, M.; Ganzleben, S.; Hanft, D.; Schmidt, H.-W.; Kristiansen, M.; Smith, P.; Stoll, K.; Mader, D. and Hoffmann, K. Macromolecules 2005, 38, 3688.

13. Zhang, Y. F.; Chang, Y.; Li, X. and Xie, D. Journal of Macromolecular Science Part B-Physics 2011, 50, 266.

14. Gahleitner, M.; Grein, C.; Kheirandish, S. and Wolfschwenger, J. International Polymer Processing 2011, 26, 2.

15. Kumaraswamy, G.; Issaian, A. M. and Kornfield, J. A. Macromolecules 1999, 32, 7537.

16. Kumaraswamy, G.; Verma, R. K.; Issaian, A. M.; Wang, P.; Kornfield, J. A.; Yeh, F.; Hsiao, B. S. and Olley, R. H. Polymer 2000, 41, 8931.

17. Yang, L.; Somani, R. H.; Sics, I.; Hsiao, B. S.; Kolb, R.; Fruitwala, H. and Ong, C. Macromolecules 2004, 37, 4845.

18. Zuo, F.; Keum, J. K.; Yang, L.; Somani, R. H. and Hsiao, B. S. Macromolecules 2006, 39, 2209.

19. Pantani, R.; Coccorullo, I.; Speranza, V. and Titomanlio, G. Prog. Polym. Sci. 2005, 30, 1185.

20. Pae, K., D. and Sauer, J., A. J. Appl. Polym. Sci. 1968, 12, 1901.

21. Wunderlich, B. Macromolecular Physics; Academic Press, London, 1979.

22. Busfield, W. K. and Blake, C. S. Polymer 1980, 21, 35.

23. Tanaka, H. and Korogi, F. Eur. Polym. J. 1988, 24, 759.

24. Poussin, L.; Bertin, Y. A.; Parisot, J. and Brassy, C. Polymer 1998, 39, 4261.

25. Gahleitner, M.; Fiebig, J.; Wolfschwenger, J.; Dreiling, G. and Paulik, C. Journal of Macromolecular Science-Physics 2002, B41, 833.

26. Natale, R.; Russo, R. and Vittoria, V. J. Mater. Sci. 1992, 27, 4350.

27. Martorana, A.; Piccarolo, S. and Sapoundjieva, D. Macromolecular Chemistry and Physics 1999, 200, 531.

28. Hedesiu, C.; Demco, D. E.; Kleppinger, R.; Poel, G. V.; Gijsbers, W.; Blumich, B.; Remerie, K. and Litvinov, V. M. Macromolecules 2007, 40, 3977.

29. Zia, Q.; Radusch, H. J. and Androsch, R. Polymer 2007, 48, 3504.

30. Varga, J. In Crystallization, Melting and Supermolecular Structure of Isotactic Polypropylene, Karger-Kocsis, J., Ed.; Chapmann\&Hall, 1995, 56. 
31. Varga, J. Journal of Thermal Analysis 1989, 35, 1891.

32. Vittoria, V. In Properties of Isotactic Polypropylene; Marcell Dekker, 1990, 507.

33. Gahleitner, M.; Berneitner, K.; Neissl, W.; Paulik, C. and Ratajski, E. Polymer Testing 1995, 14, 173.

34. Doshev, P.; Kheirandish, S.; Pukánszky, B.; Menyhárd, A.; Gahleitner, M. (Borealis) Patent Eur. App. No. 10151444.6., 2010.

35. Grein, C.; Gahleitner, M.; Knogler, B. and Nestelberger, S. Rheologica Acta 2007, 46, 1083.

36. Bafna, S. S. J. Appl. Polym. Sci. 1997, 63, 111.

37. Mezger, T. In; Vincentz Network, 2006, 109.

38. Romankiewicz, A. and Sterzynski, T. Macromolecular Symposia 2002, 180, 241.

39. Pukánszky, B.; Mudra, I. and Staniek, P. Journal of Vinyl \& Additive Technology 1997, 3, 53.

40. Wunderlich, B. Thermal Analysis of Polymeric Materials; Springer, Berlin, 2005.

41. Monasse, B. and Haudin, J. M. Colloid and Polymer Science 1985, 263, 822.

42. Clark, E. J. and Hoffman, J. D. Macromolecules 1984, 17, 878.

43. Causin, V.; Yang, B.-X.; Marega, C.; Goh, S. H. and Marigo, A. Eur. Polym. J. 2009, 45, 2155.

\section{GRAPHICAL ABSTRACT}

\section{ZSUZSANNA HORVÁTH, ALFRÉD MENYHÁRD, PETAR DOSHEV, MARKUS GAHLEITNER, CORNELIA KOCK, SAEID KHEIRANDISH, JÓZSEF VARGA AND BÉLA PUKÁNSZKY}

\section{EFFECT OF MOLECULAR ARCHITECTURE ON THE CRYSTALLINE STRUCTURE AND STIFFNESS OF IPP HOMOPOLYMERS: MODELING BASED ON ANNEALING EXPERIMENTS}

Lamella thickness and crystallinity determine stiffness in isotactic polypropylene. A simple model was developed, which allows the calculation of stiffness from these parameters. Annealing studies were carried out in order to determine maximum lamella thickness and crystallinity, and predict the largest modulus, which can be achieved under practical conditions. The maximum stiffness predicted for polypropylene is $3.5 \mathrm{GPa}$. A polypropylene grade with modulus larger than $3.5 \mathrm{GPa}$ might be also produced, but only with the proper combination of molecular mass, chain regularity and the nucleating system used.

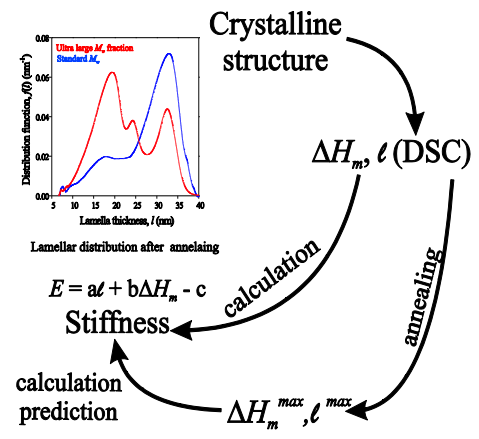


Full paper submitted for publication in Journal of Applied Polymer Science

\section{SUPPLEMENTARY INFORMATION}

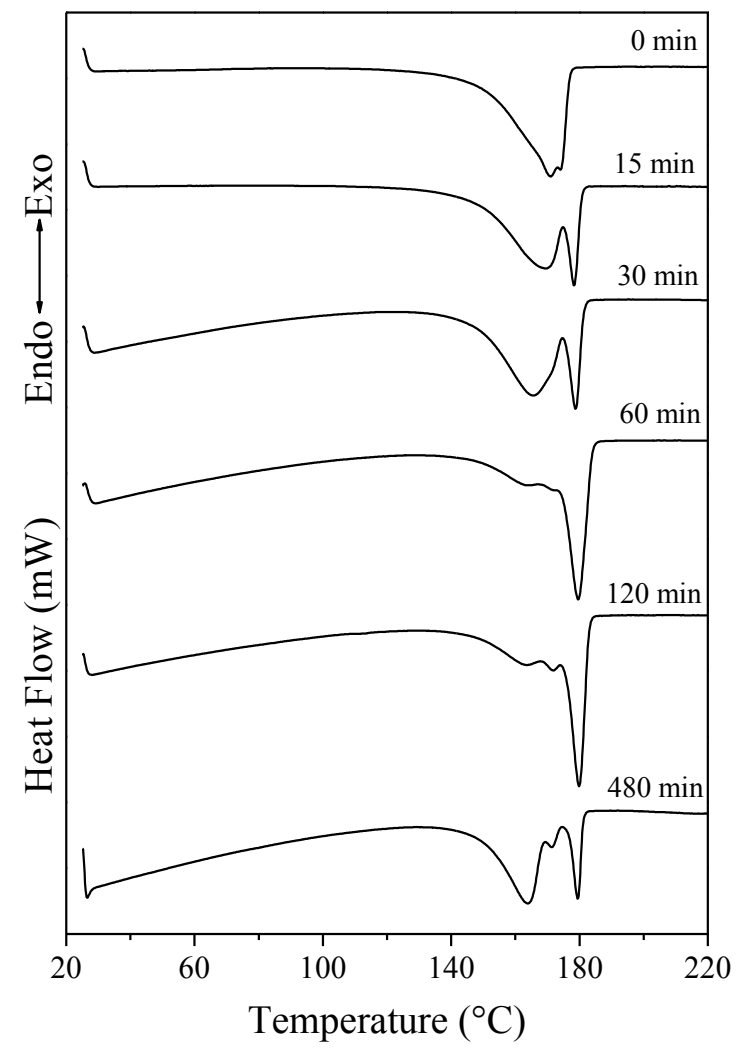

FIGURE S1 Effect of annealing on the crystalline structure of PP1; melting traces recorded after different annealing times. (SVA1776) 
Full paper submitted for publication in Journal of Applied Polymer Science

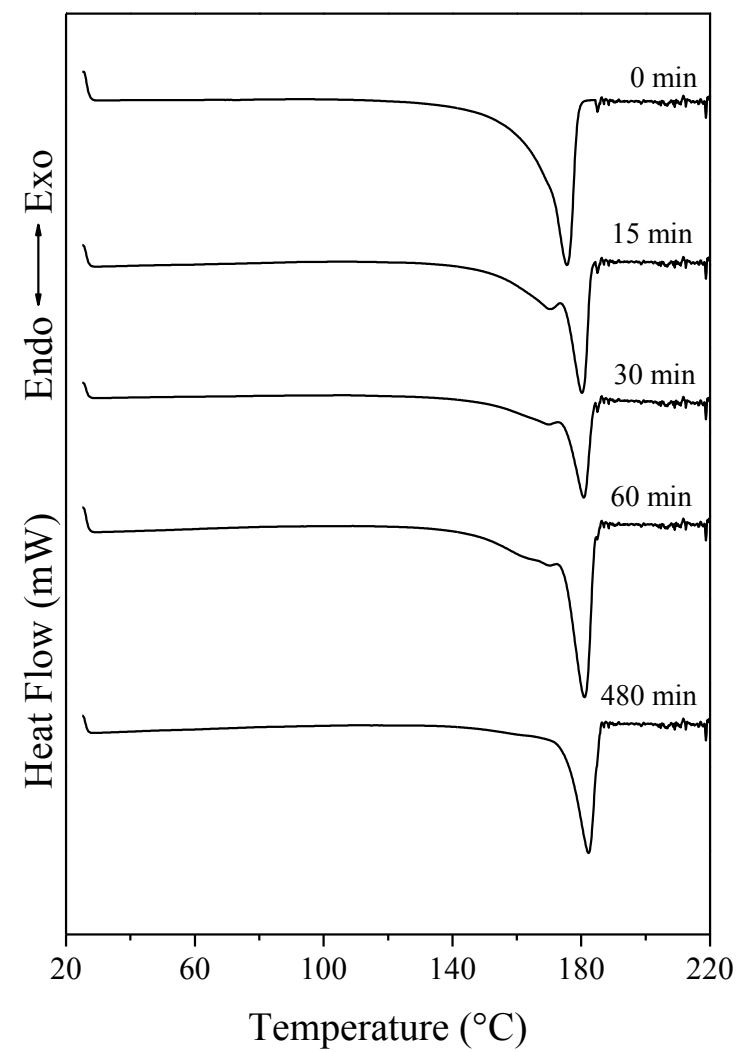

FIGURE S2 Effect of annealing on the crystalline structure of PP2; melting traces recorded after different annealing times. (SVA1803) 
Full paper submitted for publication in Journal of Applied Polymer Science

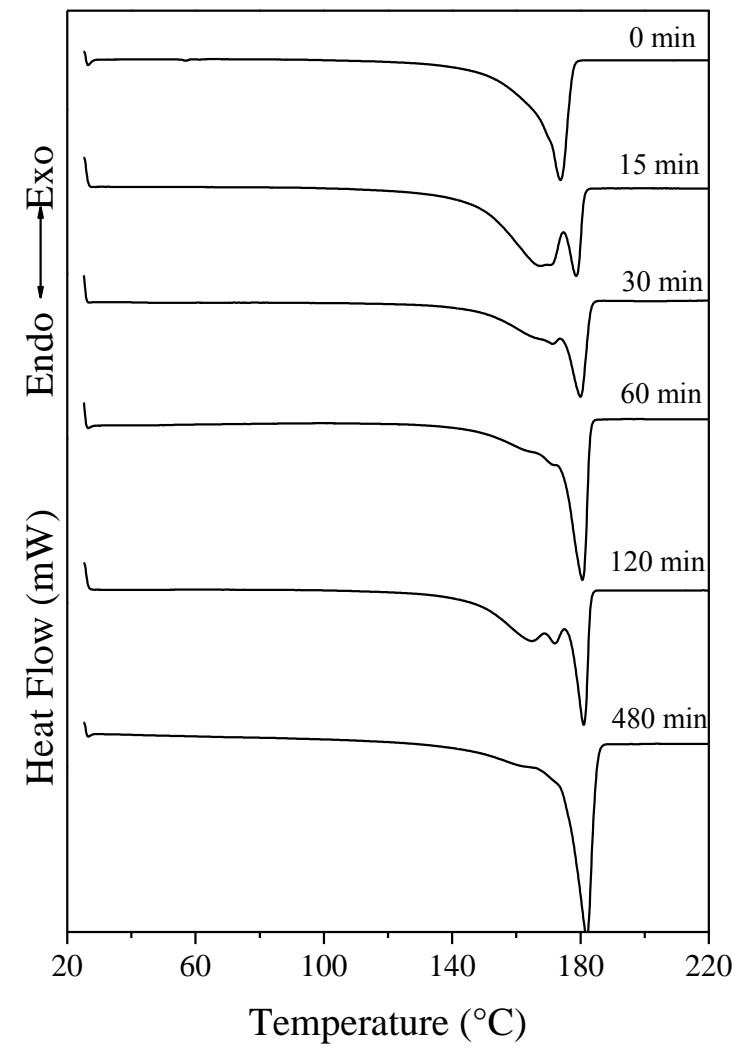

FIGURE S3 Effect of annealing on the crystalline structure of NPP1; melting traces recorded after different annealing times. (HB300TF) 
Full paper submitted for publication in Journal of Applied Polymer Science

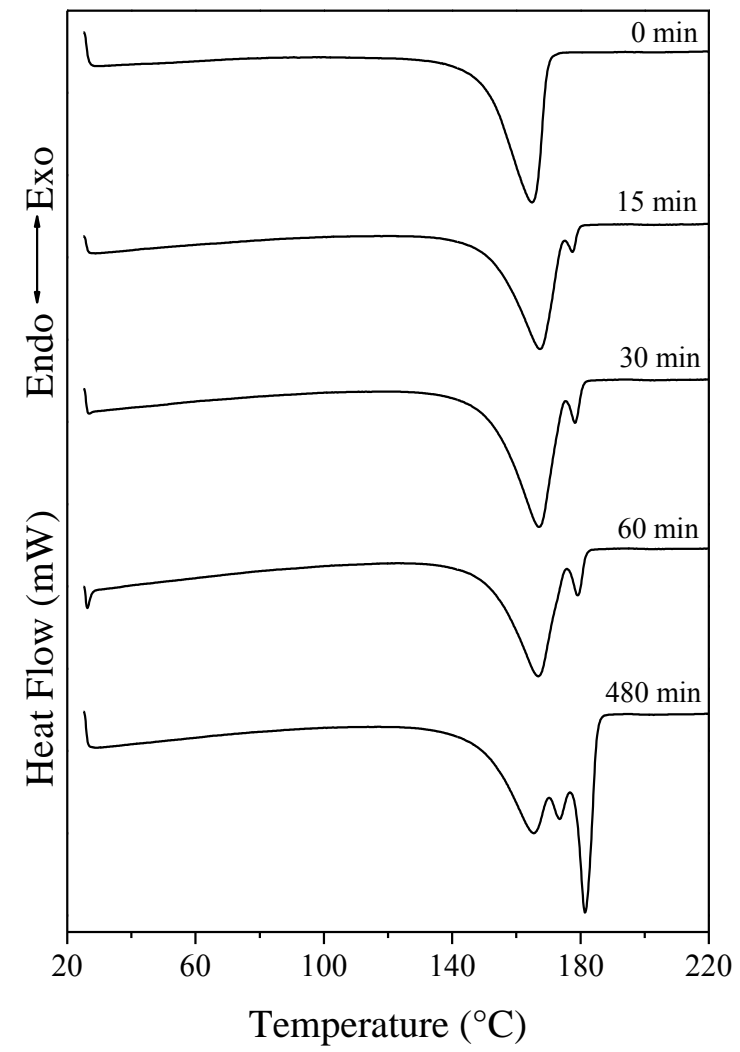

FIGURE S4 Effect of annealing on the crystalline structure of NPP2; melting traces recorded after different annealing times. (B7044) 
Full paper submitted for publication in Journal of Applied Polymer Science

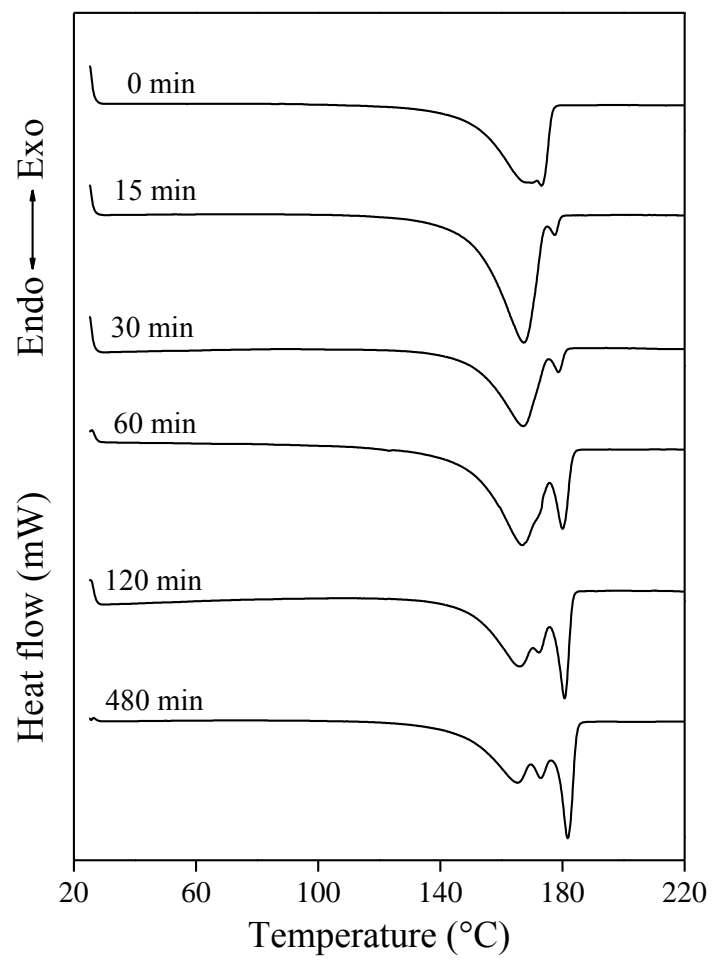

FIGURE S5 Effect of annealing on the crystalline structure of NPP3; melting traces recorded after different annealing times. (B7040) 